\title{
BLICKDIAGNOSE
}

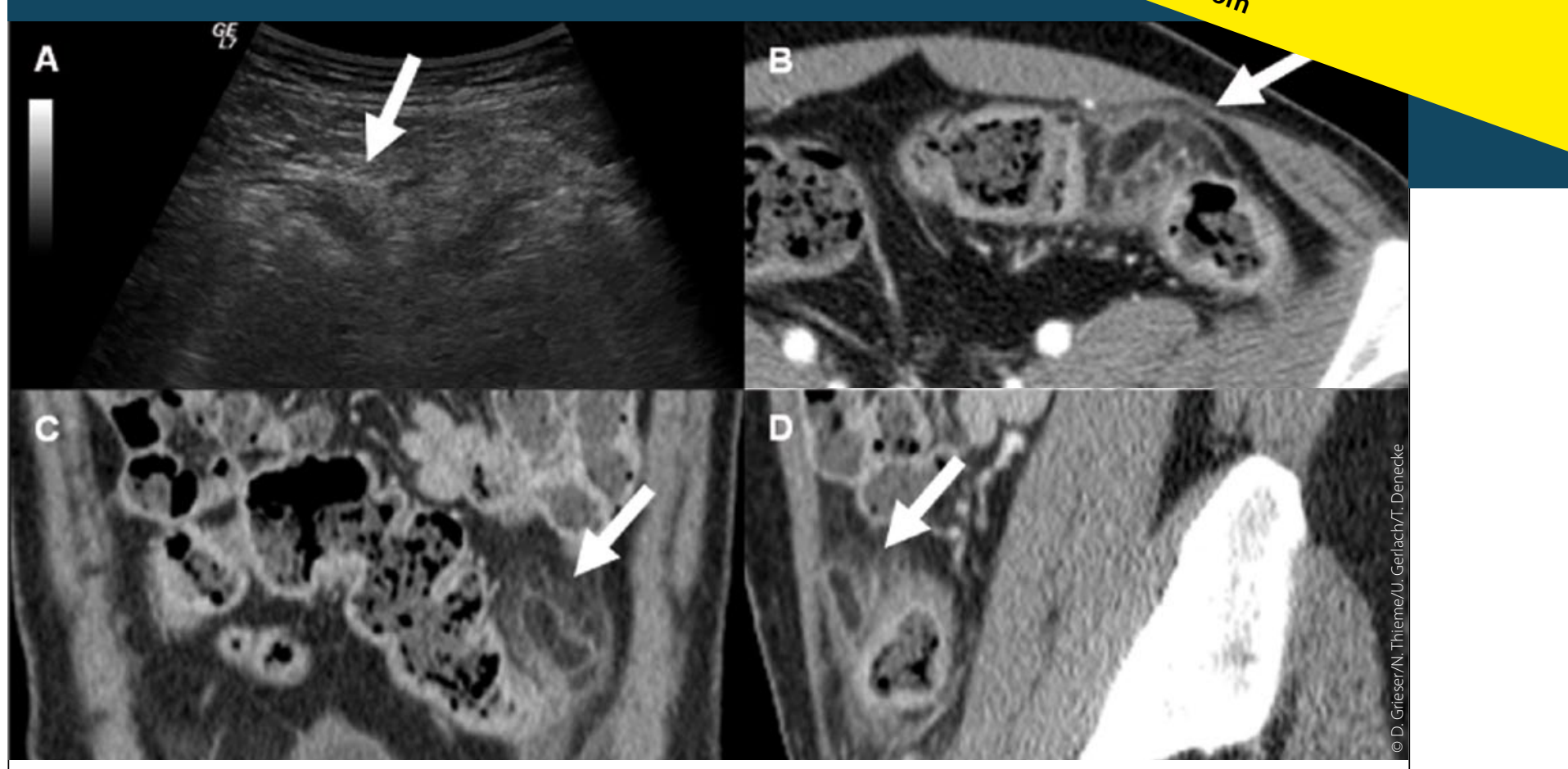

Junger Mann mit linksseitigem Unterbauchschmerz

\section{Divertikulitis? Appendizitis?}

Ein 36-jähriger Mann stellte sich mit persistierenden, diffusen linksseitigen Unterbauchschmerzen in der internistischen Rettungsstelle unseres Hauses vor. Gleichzeitig berichtete er von Diarrhöen und einer erschwerten Miktion.

- Die klinischen Laborparameter, wie auch die initiale klinische Untersuchung waren bis auf starke abdominelle linksseitige Unterbauchschmerzen unauffällig. Eine Abdomensonografie zeigte im Bereich des maximalen Schmerzpunktes im linken Unterbauch eine von der Kolonwand nach kranial ziehende kleine echoarme ovaläre Läsion sowie echoreich imbibiertes Fettgewebe (Abbildung A, weißer Pfeil) mit vermehrten Gefäßsignalen im Doppler (nicht abgebildet). Trotz des fehlenden sonografischen Nachweises eines Divertikels wurde bei initialem Verdacht auf eine Divertikulitis eine Computertomografie des Abdomens durchgeführt. Hier fand sich eine kurzstreckige Wandverdickung im descendosigmoidalen Übergang mit Nachweis einer fokalen länglichen fettäquivalenten Läsion mit umgebender Fettgewebsimbibierung und geringer umgebender Flüssigkeit ohne Hinweis auf eine akute Perforation oder eine perifokale Abszessbildung (Abbildung B [axial], C [koronar] und D [sagittal], weiße Pfeile). Korrelierend zur Sonografie zeigte sich kein Divertikelnachweis. Es wurde der Verdacht auf eine Appendicitis epiploica gestellt und die Entscheidung zur weiterführenden konservativen Therapie getroffen. Der Patient erhielt eine antibiotische Therapie für fünf Tage und wurde dann bei subjektiver Besserung der Beschwerden und ohne Infektzeichen in die ambulante Weiterbehandlung entlassen.

Bei der Appendicitis epiploica handelt es sich um eine Entzündung der, umgeben von viszeralem Peritoneum, frei endenden Fettanhängsel (so genannte Appendices epiploicae) die sich entlang der Taenia libera und Taenia omentalis des Kolons finden. Meist verursacht eine Torsion mit daraus resultierender Thrombose und Gangrän die akute Entzündung. In der Regel ist die Appendicitis epiploica selbst limitierend, die Diagnose wird in der Akutsituation meist mittels Sonografie oder Computertomografie gestellt; Laborwerte sind zumeist unauffällig. Wichtigste Differenzialdiagnose gerade bei älteren Patienten ist die Divertikulits.

Keywords: epiploitic appendicitis

- Dr. Christian Grieser ${ }^{1}$, Dr. Nadine Thieme' ${ }^{1}$ Dr. Undine Gerlach², PD Dr. Timm Denecke ${ }^{1}$

Charité Universitätsmedizin Berlin, Campus Virchow-Klinikum, ${ }^{1}$ Klinik für Radiologie, ${ }^{2}$ Klinik für Allgemein-, Viszeral- und Transplantationschirurgie

Augustenburger Platz 1, D-13353 Berlin 